\title{
Cardiac CT: A Sine Qua Non for Structural Heart Interventions
}

\author{
Dinesh K. Kalra \\ Division of Cardiology, Rush University Medical Center, Chicago, IL, USA
}

Johnny Nash - "I can see clearly now ... (the rain is gone)

I can see all obstacles in my way Gone are the dark clouds that had me blind It's gonna be a bright, bright sunshiny day"

Cardiac CT angiography (CTA) has become an integral tool in structural/interventional cardiology. Since the start of the century, CTA has been widely used in the planning of a variety of transcatheter procedures including valve interventions (e.g., transcatheter aortic valve replacement, MitraClip, etc.) [1,2], atrial septal defect (ASD) closure, left atrial appendage occlusion, atrial fibrillation ablation $[3,4]$, delineation of cardiac venous anatomy for lead placement in resynchronization therapy, coronary chronic total occlusion interventions, and even in virtual stenting of significant coronary lesions guided by CT-derived fractional flow reserve [5]. It is also commonly used for follow-up for potential complications such as paravalvular regurgitation, device migration or leaks [6], and thrombus formation [7]. In many of these applications, it has proven superior to transthoracic (TTE) or transesophageal echocardiography (TEE), and in some cases, it has supplanted the need for pre- and intra-procedural TEE [8-10]. CTA can also reveal information about structures that are difficult to visualize with TEE, for example circumflex artery compression by a left atrial appendage occlusion device or erosion of an ASD closure device into adjacent structures [11-13]. These ad- vancements have been driven in large part by improved scanner technology and image resolution that allows dynamic and faster cardiac imaging with lower radiation and contrast doses than a decade ago. Wide area detectors, faster gantry rotation times, spectral CT, and newer iterative reconstruction algorithms have incrementally helped transform what began as blurry images in the early 1990 s to the submillimeter high-resolution contemporary images in clinical use today [14].

In this issue, Zhang et al. [15] studied the performance of CTA (320-slice scanner) versus TEE in predicting ASD sizing prior to transcatheter closure in 134 patients who had the diagnosis of a secundum defect established beforehand by TTE. The majority of the patients $(n=121)$ had their closure guided only by a preprocedural CTA, while only 13 patients had TEE (and CTA) prior. Intraprocedurally, only TTE was used to guide the closure. Predicted ASD device size had a higher degree of correlation with actual device size used for CTA versus TEE ( $r=$ 0.96 vs. 0.68 ). Procedural success was $99.2 \%$ for the CTAguided group, and reproducibility of the measurements was high, as was safety, with lower rates of residual shunt and arrhythmia than similar prior larger studies that used a TEE sizing approach [16].

ASD is present in $10 \%$ of all congenital heart disease cases at birth; its incidence is about 4 per 10,000 live births [17]. Early studies comparing TTE, TEE, and CTA using an earlier generation 64-slice scanner showed that TTE

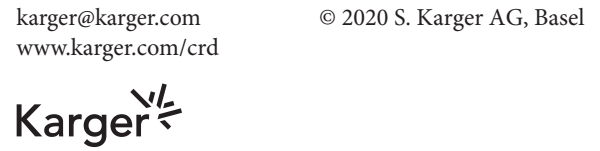

Dinesh K. Kalra, MD, FACC, FSCCT, FSCMR 
underestimated the defect size, while there was a good correlation between TEE and CTA $(\kappa=0.64)$ [18].

Even though TEE is relatively safe, it is semi-invasive, and potential complications include oropharyngeal injury, hoarseness, bleeding, respiratory depression, and esophageal rupture. Furthermore, TEE may result in an underestimation of the defect size due to changes in atrial and shunt size induced by fasting state and/or sedation and motion artifacts. CTA can be easily done even in pediatric patients, has a scan time of a few seconds, and does not need sedation or anesthesia or fasting state. It also provides isotropic voxel data with superior spatial resolution in a true 4-dimensional sense; it is superior to TEE in accurate dimensions of the rims, especially for sizing of the posteroinferior rim [18], and it provides optimal fluoroscopic angles to guide the interventionalist. Patients with a rim of $<3 \mathrm{~mm}$ are at higher risk of injury or device failure with transcatheter closure $[19,20]$. Furthermore, it can detect ancillary cardiac pathology that may not have been previously suspected - such as anomalous pulmonary venous connections, sinus venosus ASD, thrombus, coronary anomalies, etc. [21-23]. In the current study [15], for example, 1 patient had a large defect without an inferior rim and needed open surgical repair, while another patient had pulmonary artery stenosis. Similarly, CTA can be used for diagnosis and preprocedural planning of a patent foramen ovale which is present in approximately $20-25 \%$ of all individuals and plays a role in cryptogenic strokes [24, 25].

Since reformatted CTA images allow intuitive visualization in multiple planes which can be rotated by the viewer to get a full understanding of the relationships between adjacent structures, it allows for precise procedural planning especially in complex congenital heart diseases. CTA also allows for the creation of $3 \mathrm{D}$ printed models which are useful for procedural guidance in conjunction with only fluoroscopy without the need for TEE [26-28].
When images are acquired by retrospective (as opposed to prospective) gating, CTA can also provide data on shunt fraction, right ventricular volumes, and ejection fraction if needed [8]. Successful percutaneous closure requires precise information on ASD shape, size, rim lengths in all 4 directions, and location with respect to surrounding anatomy to guide appropriate delivery catheter and device choice and successful deployment [29]. The high-quality images of the pulmonary veins, coronary sinus, and rim dimensions allows superior visualization compared to TEE which may be compromised by esophageal angulation/location of the left atrium and tangential imaging planes.

Zhang et al.'s study [15] adds nicely to the growing experience on the utility of CTA to guide ASD closure although few shortcomings should be borne in mind. $\mathrm{Pa}$ tient follow-up was short (1 month). Radiation (especially in young patients) and iodinated contrast exposure are additional considerations - to further reduce radiation doses, prospective EKG gating at end systole (to acquire the largest ASD dimensions) can be used instead of retrospective gating. Larger prospective trials with randomized assignment to TEE or CTA will be needed to answer further important questions such as the impact on procedure times, length of stay, long-term safety, and cost effectiveness.

While it has always been true that seeing is believing, it is now apparent that seeing more clearly makes interventions in structural heart disease better and safer.

\section{Conflict of Interest Statement}

The author declares that there are no conflicts of interest.

\section{Funding Sources}

There is no funding to be declared.

\section{References}

1 Blanke P, Weir-McCall JR, Achenbach S, Delgado V, Hausleiter J, Jilaihawi $\mathrm{H}$, et al. Computed tomography imaging in the context of transcatheter aortic valve implantation (TAVI) / transcatheter aortic valve replacement (TAVR): An expert consensus document of the Society of Cardiovascular Computed Tomography. J Cardiovasc Comput Tomogr. 2019 Jan - Feb;13(1):1-20.
2 Blanke P, Naoum C, Webb J, Dvir D, Hahn RT, Grayburn P, et al. Multimodality Imaging in the Context of Transcatheter Mitral Valve Replacement: Establishing Consensus Among Modalities and Disciplines. JACC Cardiovasc Imaging. 2015 Oct;8(10):1191208.
3 Saucedo J, Martinho S, Frankel D, Slim AM, Eckart RE. Exclusion of left atrial appendage thrombus using single phase coronary computed tomography as compared to transesophageal echocardiography in patients undergoing pulmonary vein isolation. ISRN Cardiol. 2014 Feb;2014:838727. 
4 Bilchick KC, Mealor A, Gonzalez J, Norton P, Zhuo D, Mason P, et al. Effectiveness of integrating delayed computed tomography angiography imaging for left atrial appendage thrombus exclusion into the care of patients undergoing ablation of atrial fibrillation. Heart Rhythm. 2016 Jan;13(1):12-9.

5 Kim KH, Doh JH, Koo BK, Min JK, Erglis A, Yang HM, et al. A novel noninvasive technology for treatment planning using virtual coronary stenting and computed tomography-derived computed fractional flow reserve. JACC Cardiovasc Interv. 2014 Jan;7(1):72-8.

6 Lee T, Tsai IC, Fu YC, Jan SL, Wang CC, Chang Y, et al. MDCT evaluation after closure of atrial septal defect with an Amplatzer septal occluder. AJR Am J Roentgenol. 2007 May; 188(5):W431-9.

7 Marwan M, Mekkhala N, Göller M, Röther J, Bittner D, Schuhbaeck A, et al. Leaflet thrombosis following transcatheter aortic valve implantation. J Cardiovasc Comput Tomogr. 2018 Jan - Feb;12(1):8-13.

8 Quaife RA, Chen MY, Kim M, Klein AJ, Jehle A, Kay J, et al. Pre-procedural planning for percutaneous atrial septal defect closure: transesophageal echocardiography compared with cardiac computed tomographic angiography. J Cardiovasc Comput Tomogr. 2010 Sep-Oct;4(5):330-8.

9 Osawa K, Miyoshi T, Morimitsu Y, Akagi T, Oe H, Nakagawa K, et al. Comprehensive assessment of morphology and severity of atrial septal defects in adults by CT. J Cardiovasc Comput Tomogr. 2015 Jul-Aug;9(4):354-61.

10 Yamasaki Y, Nagao M, Kawanami S, Kamitani T, Sagiyama K, Yamanouchi T, et al. Onestop shop assessment for atrial septal defect closure using 256-slice coronary CT angiography. Eur Radiol. 2017 Feb;27(2):697-704.

11 Katona A, Temesvári A, Szatmári A, Nemes A, Forster T, Fontos G. Left circumflex coronary artery occlusion due to a left atrial appendage closure device. Postepy Kardiol Interwencyjnej. 2015;11(1):69-70.
12 Lindner S, Behnes M, Wenke A, Sartorius B, Dieker W, Ansari U, et al. Relation of left atrial appendage closure devices to topographic neighboring structures using standardized imaging by cardiac computed tomography angiography. Clin Cardiol. 2019 Feb;42(2): 264-9.

13 Soschynski M, Capilli F, Ruile P, Neumann F-J, Langer M, Krauss T. Post-TAVI followup with MDCT of the valve prosthesis: technical application, regular findings and typical local post-interventional complications. Rofo. 2018 Jun;190(6):521-30.

14 Nicol ED, Norgaard BL, Blanke P, Ahmadi A, Weir-McCall J, Horvat PM, et al. The Future of Cardiovascular Computed Tomography: Advanced Analytics and Clinical Insights. JACC Cardiovasc Imaging. 2019 Jun;12(6): 1058-72.

15 Zhang X, Huang Y, Wang L, Ye L, Tang J. Transcatheter closure of atrial septal defects with cardiac computed tomography sizing: 8 -year single-center practice. Cardiology. https://doi.org/10.1159/000508650.

16 Wang JK, Tsai SK, Lin SM, Chiu SN, Lin MT, $\mathrm{Wu} \mathrm{MH}$. Transcatheter closure of atrial septal defect without balloon sizing. Catheter Cardiovasc Interv. 2008 Feb;71(2):214-21.

17 Dickinson DF, Arnold R, Wilkinson JL. Congenital heart disease among 160480 liveborn children in Liverpool 1960 to 1969. Implications for surgical treatment. Br Heart J. 1981 Jul;46(1):55-62.

18 Ko SF, Liang CD, Yip HK, Huang CC, Ng SH, Huang CF, et al. Amplatzer septal occluder closure of atrial septal defect: evaluation of transthoracic echocardiography, cardiac CT, and transesophageal echocardiography. AJR Am J Roentgenol. 2009 Dec;193(6):1522-9.

19 Webb G, Gatzoulis MA. Atrial septal defects in the adult: recent progress and overview. Circulation. 2006 Oct;114(15):1645-53.

20 Amedro P, Bayburt S, Assaidi A, Kreitmann B, Habib G, Fouilloux V, et al. Should transcatheter closure of atrial septal defects with inferior-posterior deficient rim still be attempted? J Thorac Dis. 2019 Mar;11(3):70816.
21 Peirone A, Contreras A, Zangroniz P, Pedra C. Percutaneous closure of atrial septal defects in patients with an aberrant retroaortic coronary artery: is it safe? Congenit Heart Dis. 2014 Sep-Oct;9(5):E163-8.

22 Shetty LH, Ramesh D, Kr SK, Manjunath CN. Imaging essentials before transcatheter closure of an atrial septal defect: detection of an unusual contraindication. J Cardiol Cases. 2016 Feb;13(4):109-11.

23 Gertz ZM, Strife BJ, Shah PR, Parris K, Grizzard JD. CT angiography for planning of percutaneous closure of a sinus venosus atrial septal defect using a covered stent. J Cardiovasc Comput Tomogr. 2018 Mar - Apr;12(2): 174-5.

24 Kosehan D, Akin K, Koktener A, Cakir B, Aktas A, Teksam M. Interatrial shunt: diagnosis of patent foramen ovale and atrial septal defect with 64-row coronary computed tomography angiography. Jpn J Radiol. 2011 Oct; 29(8):576-82.

25 Mojadidi MK, Zaman MO, Elgendy IY, Mahmoud AN, Patel NK, Agarwal N, et al. Cryptogenic Stroke and Patent Foramen Ovale. J Am Coll Cardiol. 2018 Mar;71(9):1035-43.

26 Goo HW, Park IS, Ko JK, Kim YH, Seo DM, Park JJ. Computed tomography for the diagnosis of congenital heart disease in pediatric and adult patients. Int J Cardiovasc Imaging. 2005 Apr-Jun;21(2-3):347-65.

27 Rajiah P, Schoenhagen P. The role of computed tomography in pre-procedural planning of cardiovascular surgery and intervention. Insights Imaging. 2013 Oct;4(5):671-89.

28 Thakkar AN, Chinnadurai P, Breinholt JP, Lin $\mathrm{CH}$. Transcatheter closure of a sinus venosus atrial septal defect using 3D printing and image fusion guidance. Catheter Cardiovasc Interv. 2018 Aug;92(2):353-7.

29 White HD, Halpern EJ, Savage MP. Imaging of adult atrial septal defects with CT angiography. JACC Cardiovasc Imaging. 2013 Dec; 6(12):1342-5.
Cardiac CT: A Sine Qua Non for

Structural Heart Interventions
Cardiology 2020;145:663-665

DOI: $10.1159 / 000509466$ 